\section{As funções de um cérebro darwinista: Guedes Cabral e o evolucionismo de Funções do cérebro (1876)}

\section{The workings of a Darwinist brain: Guedes Cabral and the evolutionism of Funções do cérebro (1876)}

\author{
Roberto Sobreira Pereira Filho \\ Doutorando em Ensino de Biociências e Saúde/ \\ Instituto Oswaldo Cruz/Fundação Oswaldo Cruz (IOC/Fiocruz). \\ Av. Brasil, 4365/Pavilhão Arthur Neiva \\ 21045-900 - Rio de Janeiro - RJ \\ betoquiniro@yahoo.com.br \\ Ricardo Waizbort \\ Pesquisador do IOC/Fiocruz. \\ Av. Brasil, 4365/Pavilhão Arthur Neiva \\ 21045-900 - Rio de Janeiro - RJ \\ ricw@ioc.fiocruz.br
}

Recebido para publicação em junho de 2011.

Aprovado para publicação em abril de 2012.
PEREIRA FILHO, Roberto Sobreira; WAIZBORT, Ricardo. As funções de um cérebro darwinista: Guedes Cabral e o evolucionismo de Funções do cérebro (1876). História, Ciências, Saúde Manguinhos, Rio de Janeiro, v.20, n.4, out.-dez. 2013, p.1585-1604.

\section{Resumo}

O livro Funções do cérebro, do médico Domingos Guedes Cabral, é reconhecido como um dos primeiros trabalhos nacionais a defender teorias darwinistas. Ciente da necessidade de mais estudos sobre a recepção do evolucionismo no Brasil, este trabalho investiga a referida obra procurando esclarecer como Guedes Cabral utilizou o evolucionismo em sua argumentação e demonstrar a finalidade de seus argumentos no contexto histórico apresentado. Os resultados apontam para o uso do evolucionismo como parte tanto de um projeto ideológico quanto de uma teoria eugênica incipiente, desenvolvida posteriormente, no início do século XX.

Palavras-chave: história da medicina; história do darwinismo; recepção do evolucionismo no Brasil; Domingos Guedes Cabral (1852-1883); eugenia.

\section{Abstract}

The book Funções do cérebro (Workings of the brain), by physician Domingos Guedes Cabral, is recognized as one of the first Brazilian works to defend Darwinist theories. In light of the need for more studies on the reception of evolutionism in Brazil, the article investigates this book in an effort to reveal how Guedes Cabral used evolutionism in his argumentation and to reveal the purpose of his arguments within a historical context. Findings indicate that Guedes Cabral relied on evolutionism as part of both an ideological project and an incipient eugenic theory, later developed in the early twentieth century.

Keywords: history of medicine; history of Darwinism; reception of evolutionism in Brazil; Domingos Guedes Cabral (18521883); eugenics. 
$\mathrm{E}_{\mathrm{p}}$ m setembro de 1875, o estudante de medicina Domingos Guedes Cabral (1852-1883) foi o pivô de um acontecimento inédito desde a fundação da Faculdade de Medicina da Bahia: sua tese inaugural, necessária para o recebimento de seu diploma, foi recusada (Almeida, 2005). A acusação que partia dos professores apontava para uma incongruência entre as ideias do aluno e aquelas defendidas pela instituição. Se por um lado a tese Funções do cérebro já representaria um grande problema para a faculdade devido a seu conteúdo profundamente materialista, por outro questões diversas traziam dificuldades adicionais a sua defesa: a origem familiar do doutorando, que participava das muitas disputas no campo político baiano; o fato de Guedes Cabral ter dirigido um jornal republicano e anticlerical; sua defesa de que seria desnecessária a existência de um sistema judiciário, opinião que o colocava em conflito com os bacharéis do direito; entre outras questões polêmicas (Almeida, El-Hani, 2010). Para que pudesse formar-se, o jovem estudante precisou realizar outro trabalho que fosse aceito por seus professores. Redigido às pressas, Qual o melhor tratamento para a febre amarela?, a alternativa apresentada, garantiu o diploma de Guedes Cabral. Um ano depois, a tese recusada, a partir da intervenção de colegas indignados com a postura autoritária da faculdade, transformou-se em livro homônimo, assinado, anonimamente em dedicatória, pelos 'doutorandos de 1875'.

Funções do cérebro (Cabral, 1876), o livro publicado após a censura, é o principal objeto de estudo deste artigo. ${ }^{1}$ Sua relevância histórica deve-se ao fato de ser considerado um dos primeiros trabalhos darwinistas ${ }^{2}$ defendidos no Brasil (Romero, 1969; Collichio, 1988). Por outro lado, a importância do darwinismo como referência para os intelectuais brasileiros no último quartel do século XIX é amplamente reconhecida pela historiografia especializada. Partindo dessas considerações, este trabalho persegue dois objetivos correlatos: esclarecer como Guedes Cabral compreendeu e utilizou o evolucionismo em sua argumentação e demonstrar a finalidade do argumento de Guedes Cabral, ou seja, que sentido suas ideias possuem.

Nossa hipótese central é de que a defesa do evolucionismo em Funções do cérebro, além de representar adesão sincera a uma teoria científica em voga nos debates contemporâneos, corresponda também a um projeto ideológico. Empregamos aqui o termo 'ideológico' como o uso de uma ideia ou conjunto de ideias em vista de uma determinada finalidade: no caso de Guedes Cabral, o darwinismo, entendido como um conjunto de ideias, foi utilizado em vista da legitimação da medicina oitocentista, cujo processo de institucionalização ocorreu ao longo do século XIX. Em torno dessa hipótese central desenvolvemos ainda duas questões. Em primeiro lugar, demonstramos por que não acreditamos que Funções do cérebro seja uma consideração ingênua sobre a fisiologia cerebral. Sustentamos que as posições de Guedes Cabral em relação à institucionalização da medicina formaram com as questões teóricas do cérebro uma mescla inextrincável, em que não se separam com clareza os domínios político e intelectual. Em segundo lugar, entendemos que a forma como Guedes Cabral desenvolve o evolucionismo em sua argumentação não se restrinja apenas à esfera biológica, mas implique uma visão geral da realidade inteiramente nova, apresentada e defendida pelo médico a partir de sua argumentação.

Como argumento dessa posição, realizamos uma leitura crítica do conteúdo de Funções do cérebro fundamentada em dois pontos. Para compreender como Guedes Cabral entendeu e desenvolveu a teoria da evolução em sua obra, baseamo-nos nos trabalhos de alguns dos evolucionistas mais influentes do século XIX, como Jean-Baptiste Lamarck (1744-1829), 
Herbert Spencer (1820-1903), Charles Darwin (1809-1882) e Ernst Haeckel (1834-1919), ao mesmo tempo em que também utilizamos as análises de John Greene (1917- ) e Ernst Mayr (1904-2005) acerca dos significados do darwinismo. Para compreender a proposta de Guedes Cabral na defesa do evolucionismo em meados da década de 1870 no Brasil, ou seja, para compreender o sentido de seus argumentos, baseamo-nos em alguns trabalhos historiográficos específicos sobre o período, como aqueles de Roque Spencer de Barros (1986), Flávio Edler (1992) e Angela Alonso (2002), entre outros.

A exposição é iniciada com uma breve consideração sobre o darwinismo e suas definições possíveis, procurando estabelecer um critério para compreender como essa teoria pode ser interpretada em Funções do cérebro. Estabelecido esse critério, ele é utilizado para fazer uma análise das ideias contidas no livro de Guedes Cabral, procurando então esclarecer o significado do evolucionismo dentro do trabalho que desenvolveu.

\section{Ser ou não ser darwinista... é essa a questão?}

Embora Funções do cérebro seja apontado pela historiografia especializada como manifestação darwinista, não pretendemos averiguar a legitimidade do darwinismo de Guedes Cabral, ou seja, se o autor é realmente darwinista ou não. Nossa proposta busca compreender de que maneira essa teoria foi compreendida e utilizada como recurso argumentativo para a tese defendida pela personagem, nesse caso específico, acerca da fisiologia cerebral. A questão, portanto, foge do esquema 'ser ou não ser darwinista': busca-se compreender a relação entre a personagem e as ideias, procurando esclarecer o processo de interpretação e uso dessa teoria científica europeia dentro da medicina oitocentista brasileira.

Se por um lado pode ser tarefa inglória encontrar consenso acerca do significado do termo darwinismo, visto que distintos campos como a história, a filosofia e a biologia apontam para diferentes visões, por outro lado trabalhar com algumas das definições presentes nessas disciplinas pode facilitar a compreensão da teoria dentro da própria multiplicidade que a caracteriza (Bizzo, 1991). Enquanto, por exemplo, um historiador procura o darwinismo como uma teoria dentro de seu lugar no tempo, um biólogo preocupa-se principalmente em entender sua importância para a investigação biológica. Entender quais 'darwinismos' possam estar presentes em Funções do cérebro ajudará, portanto, a esclarecer de que forma Guedes Cabral utilizou a teoria em seu trabalho.

Em sua leitura das ideias desenvolvidas em The origin of species, Mayr (1998) entende que o darwinismo, nos limites de uma investigação biológica, constitui-se de cinco teorias diferentes e inter-relacionadas, cujo desconhecimento pode causar confusão quando de sua interpretação. Essas teorias, apesar de consideradas em conjunto pelo naturalista inglês, não formam um todo indivisível, o que é corroborado ao se perceber que vários evolucionistas aceitaram algumas e negaram outras, como é caso da quase pronta aceitação da origem comum e rejeição da seleção natural em meados do século XIX. São elas: (1) 'fato da evolução': é a teoria de que o mundo não é constante, mas sim produto de um processo contínuo de mudança. Segundo o próprio Mayr, a despeito das especulações de diferentes filósofos, até 1859 predominava a opinião de que o mundo era estável; (2) 'origem comum': considerada por Mayr a primeira revolução darwiniana, ao subtrair o homem de sua posição privilegiada na 
natureza, essa teoria estabelece que todos os organismos provêm de um ancestral comum, por um processo contínuo de ramificação; (3) 'gradualismo': é a teoria que afirma que a evolução ocorre lentamente, sem saltos ou eventos repentinos. Essa observação foi um dos pontos mais criticados de suas ideias, já que a maioria das descobertas paleontológicas apontava para o aparecimento súbito de espécies fósseis, com total ausência de elos intermediários; (4) 'especiação': é a teoria da multiplicação das espécies, e de como ocorre essa diferenciação. Com essa ideia, Darwin procurava explicar que o processo de emergência de novas espécies é um processo natural, ocorrendo dentro de circunstâncias específicas, como isolamento geográfico e outros processos; (5) 'seleção natural': Mayr a considera a segunda revolução darwiniana, por explicar o mundo natural de forma puramente material e não teleológica. A seleção natural é o mecanismo que Darwin usa para explicar, principalmente, como ocorre a adaptação dos organismos a seu meio, embora também a usasse em alguns momentos como teoria complementar à da especiação.

Wilson Frezzatti Jr. (2001), por outro lado, defende que não faz sentido identificar o darwinismo como derivação simplista daquelas ideias desenvolvidas ao longo de The origin of species. Esse autor entende que o darwinismo não surgiu com essa obra, mas foi construído ao longo do século XIX através de uma confluência de questões científicas, religiosas, filosóficas e políticas. O darwinismo estaria, assim, submetido à contingência histórica. Como exemplo de sua afirmação, Frezzatti Jr. cita a diferença entre as definições de Thomas H. Huxley (18251895) e A. R. Wallace (1823-1913): enquanto para o primeiro o darwinismo significaria uma arma política liberal, para o segundo se limitaria ao âmbito científico. Importa, assim, entender quais questões históricas estão relacionadas ao darwinismo quando da procura de seu significado. Frezzatti Jr. cita ainda a grande repercussão do darwinismo entre as ciências sociais do século XIX como evidência de seu impacto fora do campo da biologia. O autor lembra que, como a seleção natural não teve ampla aceitação entre a comunidade científica a partir da publicação, em 1859, de The origin of species, grande parte do sucesso do darwinismo entre os meios científicos europeus se deveu a sua assimilação pela esfera sociológica, legitimando movimentos nacionalistas e eugênicos que já grassavam na Europa mesmo antes de Darwin. De acordo com Frezzatti Jr., portanto, para compreender o darwinismo e seu impacto fora das ciências naturais é necessário compreender quais contingências históricas associam-se a seu contexto histórico específico. Compreender de que maneira Guedes Cabral entendeu o darwinismo/evolucionismo implica, então, compreender qual o lugar epistemológico dessas ideias na segunda metade do século XIX, período em que o autor defendeu sua tese.

Greene (1981) defende a ideia de que o darwinismo do século XIX engloba não só uma teoria biológica ou filosófica, mas uma concepção mais ampla, que chegaria a reconfigurar a interpretação de conceitos como natureza, Deus, homem, história, ciência e sociedade. $\mathrm{O}$ darwinismo oitocentista seria uma teoria suficientemente penetrante para ser caracterizada como uma 'visão de mundo', capaz de provocar novos olhares sobre velhos conceitos. Embora Darwin não tenha deixado nenhum material que explicitasse sua visão geral da realidade, essa pode ser inferida também a partir dos escritos de seus parceiros intelectuais, como Huxley, Wallace e Spencer. A 'visão de mundo' provocada pelo darwinismo seria, de acordo com Greene, a consequência da adesão dos darwinistas a um conjunto de teorias presentes no pensamento ocidental muito antes de Darwin e seu círculo intelectual, que as teriam 
sintetizado num construto teórico coerente. Essas teorias - materialismo, evolucionismo, laissez-faire, estudo das leis do desenvolvimento histórico e empirismo - deram a Darwin, Spencer, Wallace e Huxley igual visão geral de realidade, consolidada em seus trabalhos ao longo das décadas de 1850 e 1860 . O autor procura esclarecer, entretanto, que esse darwinismo oitocentista constitui uma teoria datada historicamente, que só funcionou dessa forma dentro do período apontado, ou seja, no final do século XIX. Ainda que hoje em dia possamos considerar o darwinismo uma 'visão de mundo' particular, em oposição a uma 'visão de mundo' criacionista, por exemplo, ele perdeu algumas de suas características originais, como é o caso de sua associação às leis do desenvolvimento histórico. Greene então assume que o darwinismo, entendido por ele como um sistema conceitual, mudou ao longo do tempo, comportando hoje uma estrutura muito diferente daquela de quando surgiu.

Feitas essas considerações em relação ao darwinismo, chegamos a duas importantes conclusões: (1) embora Darwin tenha pretendido criar uma teoria biológica ao escrever The origin of species, suas ideias foram transportadas para outros campos de conhecimento e transcenderam a esfera biológica. Seria anacrônico, então, desconsiderar implicações sociais/ políticas/filosóficas na tentativa de compreender como Guedes Cabral entendeu o darwinismo; (2) o darwinismo oitocentista apresenta significado histórico único, diverso daquele que o conceito adquiriu ao longo do tempo até os dias de hoje. É patente, portanto, compreender Funções do cérebro dentro desse contexto específico, o que acredito estar bem estabelecido no trabalho de Greene (1981) quando entende ser o darwinismo do século XIX uma 'visão de mundo' singular.

Se Guedes Cabral escreveu Funções do cérebro com o intuito de apresentar uma nova teoria fisiológica sobre o cérebro, e para isso utilizou a então recente teoria darwinista, devese então procurar esse 'darwinismo biológico' em seu trabalho, o que ajudará a esclarecer como a personagem manipulou essas importantes questões científicas. Por outro lado, uma vez inserido no mesmo recorte temporal que caracterizou a recepção do darwinismo em todo o mundo, vale também observar em Funções do cérebro como o darwinismo pode ter influenciado a visão de realidade de Guedes Cabral ao travar contato com essa teoria. Com base principalmente nestas duas possíveis interpretações do darwinismo, como teoria biológica e como visão de mundo, apresentaremos agora Funções do cérebro procurando destacar de que maneira essa teoria científica aparece como um ingrediente especial nessa tese médica datada do final do oitocentos brasileiro.

\section{O livro}

Funções do cérebro (Cabral, 1876) é dividido em cinco capítulos, dentro dos quais há algumas subseções. São eles: I. O Cérebro; II. Cérebro e sensação; III. Cérebro e movimento; IV. Cérebro e pensamento, este dividido em "Relações anatomofisiológicas", "Considerações fisiopatológicas", "Mecânica cerebral", "O pensamento e as ideias" e "Há sedes distintas para as faculdades intelectuais?"; V. Cérebro e sentimento", dividido em "Os afetos" e "As paixões". Ao seguir nossa proposta inicial, contudo, não serão consideradas essas divisões, procurando enfocar alguns conceitos específicos presentes na obra. Nossa leitura apoia-se naqueles conceitos que, segundo Greene (1981), apresentam uma reconfiguração à luz do 
darwinismo: os conceitos de ciência, natureza, homem e sociedade. Não serão enfocados os conceitos de Deus e história por preferência metodológica. Dessa maneira, apresentaremos agora nossa própria divisão esquemática de Funções do cérebro, enfatizando como aparecem ao longo de suas páginas as transformações daqueles conceitos escolhidos como objetos de análise.

\section{Por uma 'verdadeira filosofia': o conceito de ciência em Funções do cérebro}

Quem quer que folheie as páginas de Funções do cérebro logo perceberá a importância que possui o conceito de ciência na argumentação de Guedes Cabral. Começando por sua epígrafe, em que o famoso fisiologista alemão Friedrich Büchner é citado como referência, o médico baiano deixa transparecer o norte que tomará em relação a sua ideia de investigação científica.

A experiência extensíssima de mais de mil anos ensinou-nos que, quanto mais estreitamente se unem nossos conhecimentos científicos à natureza e à vida terrestre, tanto mais ganham em profundidade e superfície; ao passo que as hipóteses espiritualistas e os sonhos do passado fazem-nos seguir numa medida proporcional o caminho inverso (Cabral, 1876, p.III).

Essa epígrafe prepara o terreno para as questões desenvolvidas nas páginas subsequentes do livro. A escolha das palavras de Büchner é simbólica: ela representa a tomada de uma posição dentro de uma querela científica muito debatida ao longo do século XIX, envolvendo o materialismo, o espiritualismo e a questão da legitimidade das ciências. Na Alemanha oitocentista, a rejeição crescente à Naturphilosophie fez com que todo conhecimento considerado especulativo em demasia, sem forte base empírica, fosse duramente recusado e tachado como anticientífico pelos teóricos do século XIX. A chancela científica deveria ser concedida somente àqueles trabalhos que possuíssem sólida experimentação. Nesse contexto, a filosofia materialista desenvolvida por Büchner e outros autores apresentava-se como alternativa ao idealismo romântico da Naturphilosophie, apontando para uma mudança no conceito de cientificidade do período.

Esse conceito de cientificidade característico, em que o materialismo e a rejeição de explicações espiritualistas têm papel principal, pode ser observado ao longo de toda a argumentação de Funções do cérebro. Guedes Cabral chega a fazer referência direta aos materialistas alemães, cujas opiniões compartilha em relação à cientificidade.

A sociedade, cujos destinos vão mudar, ou pelo menos modificar-se profundamente, deverá a esses novos e verdadeiros filósofos o seu maior adiantamento. Tudo quanto existe até aqui, que se funda sobre o imaginário, o hipotético, o ideal, o mitológico, o quimérico da filosofia espiritualista, tudo vai baquear inevitavelmente, à maneira dessas moles imensas de água que por muito tempo se suspendem e pairam imperiosas sobre nossas cabeças, mas que um bom dia, quando menos se espera, acabam por abater-se, por despejar-se lá do seu fictício domínio nas regiões do raio.

E o raio aqui é a verdade, o real, o sólido, o inegável da filosofia positiva.

A primeira vez que ela ergueu o colo, lá das névoas sombrias da Alemanha, onde nascera à custa das vigílias de muitos sábios, gritaram a uma os incrédulos, os ignorantes... e os padres. 
Mas, a incredulidade abisma-se já no verbo luminoso da ciência: a ignorância continua a gritar, como sempre, mas é já um grito de cólera que arranca e acabará por ser um grito de assombro... O clericalismo ... esse morrerá ... embora gritando.

E a ciência triunfará! (Cabral, 1876, p.XXVIII-XXIX).

As referências à Alemanha e a seus cientistas não são exclusividades de Guedes Cabral. Devido a seu modelo de institucionalização científica, no qual, entre outras características, as faculdades serviam também como centros de ciências práticas, a Alemanha tornou-se exemplo para as demais nações do mundo que buscavam excelência em pesquisa (Edler, 1992, p.285). No Brasil foram comuns ao longo do século XIX referências ao modelo de ensino e pesquisa científica alemã, o qual era apontado como meta a seguir.

Em contraste com a realidade alemã, Guedes Cabral questiona o status da medicina nacional. $\mathrm{O}$ foco de sua crítica envolve uma questão epistemológica relacionada ao próprio sentido e objetivo da prática da medicina.

Se se chama medicina a essa ciência (?), mísera ciência que faz vida de si mesma, a essa ciência mais pretensiosa do que sábia, mais mercantil do que humana, que roda aí a trote de carro, abroquelada em todo o rigor do charlatanismo; se se chama medicina a essa cousa que chamaremos ignóbil, ciência que abre balcão e mercadeja impudicamente na praça pública, batendo moeda sobre as dores e as misérias da humanidade; sim, se isso é medicina, então têm razão de sobejo esses senhores: mas se a medicina é cousa muito diversa disto, se a 'medicina é a ciência dos princípios e dos fatos', o complexo de todos os conhecimentos essenciais à vida do homem, se tem outro fim que não é enriquecer os charlatães - fim utilíssimo, o mais útil, diremos melhor, de quantos possa visar a inteligência do homem; então, não, perdoem-nos - a medicina filósofa, porque é ela a única verdadeira filosofia (Cabral, 1876, p.XXXIII-XXXIV; destaque nosso).

Guedes Cabral discute o uso da medicina como pesquisa científica, contrapondo a esse fim outro em moldes mais mercantis. A importância desse destaque se deve ao cenário complexo das ciências no final do século XIX brasileiro. Por um lado, eram raros os lugares em que se praticava a pesquisa científica com o caráter que hoje ocorre nas faculdades e outros centros de ciência. O Museu Nacional era um desses locais em que já ocorriam pesquisas nos moldes modernos, ou seja, com ênfase em experimentações, publicação de resultados em periódicos especializados e debate sobre demais questões científicas (Gualtieri, 2003, p.45-96). Não era, no entanto, uma regra nacional. As faculdades, por exemplo, não abrigavam a pesquisa científica, e era essa uma das principais reivindicações das personagens do período. Para elas, seria essencial uma nova postura para que a ciência pudesse prosperar e impulsionar a nação, em conformidade com o observado no caso alemão (Edler, 1992). Por outro lado, os médicos disputavam seus clientes com uma série de curandeiros/charlatões/terapeutas populares, que cada vez mais cativavam a confiança do público em detrimento da medicina alopática, essa muitas vezes agressiva e estranha às concepções de mundo do povo (Edler, 1992). O discurso de Guedes Cabral reflete uma busca de institucionalização da medicina, de sua diferenciação em relação a outros saberes e procedimentos: uma afirmação de seu suposto status superior, legítimo, 'científico'. Isso demonstra também como o conceito de medicina parece confundir-se com ciência no discurso do autor. Entendemos que esse seja um reflexo da nova perspectiva proposta para o campo médico nacional. 
Em outras passagens de Funções do cérebro, Guedes Cabral procura demonstrar sobretudo a finalidade/utilidade de sua proposta epistemológica em relação à medicina. A tônica de sua exposição aponta para a importância de demonstrar um lugar para a medicina/ciência, explicando de que forma pode ser útil e qual seu papel social.

Há quem pense até que essas afinidades, esses direitos hereditários do organismo vão a um ponto tal, que se possa até conseguir auxiliar a natureza em seu processo íntimo, para obter-se uma família dotada toda de grande inteligência, aplicando-se para isso meios análogos aos que se empregam nos animais inferiores para obter-se tal ou tal propriedade útil peculiar a certas raças.

Irá até aí a ciência?

Não lhe vemos impossíveis. A ciência de hoje é como aquele discípulo de Sócrates, que o ensinava a ensinar o que sabia. A natureza sabe a sua missão: a ciência, que é sua discípula, a ensinará a desenvolvê-la (Cabral, 1876, p.152-153).

A medicina, ou ciência no discurso de Guedes Cabral, tem o papel de guiar a natureza, auxiliá-la em sua meta. Nesse trecho o autor desenvolve uma ideia que se tornará, na virada do século XIX para o XX, um grande programa de pesquisa científica brasileiro: a eugenia. $\mathrm{O}$ melhoramento da civilização através de métodos de seleção artificial, em que os indivíduos mais robustos e de 'melhor conformação' são privilegiados em detrimento daqueles 'degenerados', ganhou muita expressão sobretudo no início do século XX, principalmente através do ativismo de Renato Kehl e outras personagens que militaram em prol de uma ação eugênica para a nação brasileira (Stepan, 2004). No âmbito de nossa discussão inicial, sobre o papel da ciência no pensamento de Guedes Cabral, é importante, contudo, atentar para a questão da utilidade do conhecimento, para a preocupação do autor em demonstrar como essa nova medicina científica que defende pode ser útil ao país. A retórica por uma medicina prática, experimental, e útil ao mesmo tempo, comprometida com o progresso e com papel claro na sociedade é apontada pela historiografia como característica da luta pela institucionalização da ciência nacional (Edler, 1992). É por uma medicina e ciência úteis, em oposição ao modelo contemporâneo vigente, de caráter bachaleresco e caracterizado pela valorização de conhecimentos enciclopédicos, que os médicos lutaram para implementar as reformas no ensino das faculdades de medicina, como aquela ocorrida em 1884. Assim como outros autores apontam o 'pasteurianismo' como o novo modelo de ciência que as personagens brasileiras passaram a defender em sua luta pela profissionalização científica (Benchimol, 1999), entendemos que o evolucionismo darwinista possa ter tido papel semelhante, representando nesse caso uma nova ciência, de cunho materialista, em contraposição ao modelo anterior, chamado por Guedes Cabral de espiritualista. ${ }^{3}$

Aceitando o evolucionismo como referência, Guedes Cabral também reconfigura outro conceito através de sua argumentação: a ideia de natureza, que veremos a seguir.

\section{Evolução, progresso, matéria e movimento: o conceito de natureza}

Grande parte da popularidade de Guedes Cabral deve-se a sua associação ao darwinismo, ainda incipiente nos debates da intelectualidade brasileira na década de 1870. Aquele leitor que procurar uma explanação teórica sofisticada sobre o darwinismo em Funções do cérebro, 
contudo, ficará um tanto decepcionado. Utilizando a análise de Mayr (1998), dos cinco componentes teóricos que esse autor aponta como estruturais do darwinismo - evolução como fato, origem comum, especiação, gradualismo e seleção natural - somente a própria ideia de evolução e a origem comum encontram-se presentes na tese do médico baiano. $\mathrm{O}$ que se pode perceber é uma apropriação mais geral do que específica do evolucionismo, em que essa ideia tem o papel de uma grande base sobre a qual Guedes Cabral estrutura sua argumentação. Isso não quer dizer, contudo, que a evolução tenha papel secundário em seu trabalho: as consequências do darwinismo permeiam as principais questões discutidas no livro.

Quanto mais perfeito, quanto mais completo é o desenvolvimento do cérebro, tanto mais se avantaja o ser na série da animalidade.

Um plano fundamental comum presidiu a organização desse órgão em todos os que o têm. A começar pelos peixes nos vertebrados, vemo-lo subir gradual e progressivamente sob a influência de causas que não devem ser outras senão as de que fala Darwin, assinalando a seleção natural na luta pela existência. E nesse desenvolvimento gradual, nessa ascendência progressiva da constituição cerebral, se alguma vez diferenças mais ou menos pronunciadas se observam, não é que se desvie a natureza, que assuma outro plano de organização, mas simplesmente que se esforça por adiantar sua obra (Cabral, 1876, p.2).

Esse é o trecho mais significativo acerca da evolução orgânica e suas causas que o autor faz em seu trabalho. A evolução introduz um mundo em transformação, em que os seres vivos se desenvolveram através de causas naturalistas e não por intervenções divinas ou espiritualistas, nas palavras do autor. Contudo, um aspecto dessas causas naturalistas chama a atenção na explanação de Guedes Cabral: a ideia de progresso inerente à evolução orgânica; progresso que, em alguns casos, faz a própria natureza 'adiantar sua obra', ou atingir estágios evolutivos mais complexos na linhagem natural.

A questão sobre a relação entre as teorias de progresso e evolução é complexa. Em obra de 1807, Lamarck (1984, p.130), por exemplo, acreditava numa constante melhoria no desenho das espécies conforme seu grau de evolução: "se a natureza não tivesse sido capaz de dotar a atividade de organização com a faculdade de aumentar gradualmente a complexidade da organização ... ela certamente nunca produziria aquela infinitamente variada multidão de animais e plantas" 4 . De forma semelhante se posicionou Spencer (2002, p.5), em 1857: "essa lei do progresso orgânico é a lei de todo progresso; quer se trate das transformações da terra, do desenvolvimento da vida em sua superfície ou do desenvolvimento das instituições políticas"; assim como Haeckel (1961, p.489), em 1868: “Baseando-se na observação paleontológica, a lei do progresso e do aperfeiçoamento prova este fato capital que, em todas as épocas da vida orgânica na Terra, houve progressão no grau de aperfeiçoamento dos seres organizados". A posição de Charles Darwin, num primeiro momento, parece ambígua. Embora se contraponha ao progresso em algumas oportunidades (Darwin, 1979, p.85, tradução da edição inglesa de 1871), em outras admite a ideia (Darwin, 1985, p.120, tradução da edição inglesa de 1859). Essa contradição, segundo Mayr (1998, p.592-593), é ilusória, pois se deve a uma questão de focos distintos: por um lado, Darwin nega a existência de mecanismos ou leis naturais que garantam a progressão na natureza: a seleção natural não garante uma progressão visível na filogenia por ser um mecanismo contingente e não teleológico; por outro, o naturalista 
inglês assume a existência de desenhos superiores ao longo de certas linhagens biológicas. O progresso evolutivo não seria necessariamente teleológico, mas fruto de uma combinação de causas contingentes que resultaram numa característica superior de algumas espécies em relação a outras.

Por acreditar numa evolução teleológica, em que o progresso tem o papel principal, o autor de Funções do cérebro se afasta da concepção darwiniana que elege a contingência como referência evolutiva, se aproximando então das ideias de Lamarck, Spencer e Haeckel. Essa relação estabelecida por Guedes Cabral entre progresso e evolução denota seu desconhecimento, ou discordância, da obra darwiniana, visto que entende ser a seleção natural a causa do progresso das espécies. Curiosamente, essa é uma versão do pensamento de Haeckel (1961, p.128), que aponta o progresso como consequência direta da ação da seleção natural: "a seleção natural é o princípio transformador mais poderoso; é também a principal alavanca do progresso, o principal agente do aperfeiçoamento". Essa observação demonstra a apropriação peculiar do evolucionismo realizada por Guedes Cabral, posto que, embora Haeckel fosse considerado darwinista, sua versão da teoria, conhecida como darwinismo (darwinismus), implicava uma série de importantes consequências filosóficas, políticas e culturais ausentes do darwinismo original, como a seleção artificial da espécie humana visando ao desenvolvimento eugênico, por exemplo. Ao aproximar-se das ideias de Haeckel, o autor de Funções do cérebro demonstra, assim, como as consequências do darwinismo, e não apenas sua estrutura conceitual, têm importante papel em seu estudo sobre o cérebro.

Assim como os evolucionistas europeus - Lamarck, Spencer, Darwin e Haeckel - Guedes Cabral também vê as leis da evolução perpassando todos os níveis da natureza. O autor de Funções do cérebro procura deixar clara sua visão acerca da relação entre os organismos 'vida e animalidade', que

são apenas, por graus, uma e a mesma cousa no fundo. Tudo que vive é animado: tudo que é animado o é porque vive.

A vida, é, pois, um sobrenome da força: animalidade - o seu mais pomposo qualificativo. O que faz germinar, crescer, florir, frutificar a planta é o mesmo que faz nascer, crescer, sentir, pensar, reproduzir-se o homem.

Quereis ainda vê-lo melhor? Atentai para a gênese, para a embriologia.

O gérmen é um e único. Afinidade química, grão polínico, espermatozoide - vocábulos distintos para nós - são apenas sinônimos na linguagem misteriosa e sábia da natureza....

A natureza não desvia seu plano, repetimos: a força é que parece mudar, mas apenas se complica. O movimento é o mesmo por toda a parte; nas moléculas do oxigênio, como na célula vegetal; no embrião animal, como no cérebro do homem (Cabral, 1876, p.112-113).

Guedes Cabral vê apenas uma diferença quantitativa entre a vida e a 'animalidade', ou mesmo entre a vida e a matéria bruta, como quando se refere às moléculas de oxigênio. Como o próprio autor chama a atenção, a diferença não é de nível, mas de grau. Essa ideia é muito diferente daquela que observamos em Lamarck (1984, p.194) (“Assim, entre os corpos brutos ou inorgânicos e os organismos vivos existe uma imensa diferença, um grande hiato, em suma, uma distinção radical de tal forma que nenhum corpo inorgânico jamais possa ser 
comparado ao mais simples dos corpos vivos”) e Spencer $(1862, \S 104)$ (“Outrossim, visto que os agregados orgânicos diferem dos outros agregados, tanto na quantidade de movimento que eles contêm quanto na quantidade de rearranjo de partes que acompanha a integração progressiva"), para quem há separação intransponível entre os níveis orgânico e inorgânico. Embora esses autores admitam que tanto a matéria bruta quanto os seres vivos estejam submetidos às mesmas causas naturalistas, não assumem que esse motivo legitime semelhança qualitativa entre os dois níveis de organização. Posição muito diferente desses dois autores é aquela defendida por Ernst Haeckel (1961, p.17). O alemão, através da filosofia com a qual se propõe superar as dicotomias existentes em favor de uma nova forma de conhecimento, o 'monismo', entende que os pares homem/natureza, matéria/espírito e orgânico/inorgânico, por exemplo, são infrutíferos para uma compreensão correta da realidade ("Chegamos assim à convicção extremamente importante de que todos os corpos conhecidos da natureza são igualmente 'animados' e que a oposição outrora estabelecida entre o mundo dos corpos vivos e o dos corpos mortos não tem razão de ser"). O corolário dessa proposta é uma paridade entre a vida e a matéria inanimada, no mesmo tom que observamos no discurso de Guedes Cabral.

Se por um lado Guedes Cabral apresenta um conceito de natureza muito semelhante àquele que Greene vê nos primeiros darwinistas, Spencer, Darwin, Wallace e Huxley, por outro lado, suas teses parecem estar ainda mais próximas daquelas de Haeckel, para quem o materialismo seria levado às últimas consequências. Mais do que mera diferença teórica, o darwinismo haeckeliano aponta para consequências distintas daquele darwinismo original de The origin of species. Para Guedes Cabral, a natureza não é estática, mas evolutiva, sendo encadeada mesmo em seus limites orgânico/inorgânico; possui também um sentido progressista bem definido e deve ser compreendida em termos de matéria e movimento. Todos esses fatores são apresentados em função da construção de uma nova visão de mundo, a qual Guedes Cabral tenta defender em oposição àquela estabelecida, que ele chama, entre outros termos, de 'espiritualista'. Essa nova natureza apresentada por Guedes Cabral serve como base para o desenvolvimento de suas principais teorias em Funções do cérebro, entre elas, a natureza do pensamento, o modo pelo qual se desenvolve o intelecto e como esse processo pode ser otimizado. Para compreender de que forma Guedes Cabral apresenta essas ideias, no entanto, precisaremos ainda compreender o novo conceito de homem que é apresentado em seu discurso.

\section{Arrancando o homem da Bíblia: o conceito de homem}

As consequências de uma natureza evolutiva, progressista e materialista podem ser mais bem observadas na nova concepção de homem que é apresentada em Funções do cérebro. Corolário óbvio do mundo em evolução é a paridade do homem com outros animais, estribada pelas ciências positivas da anatomia, embriologia e fisiologia comparadas. "O homem é, pois, apenas um macaco aperfeiçoado. Verdade cruciante para nosso orgulho, mas que, por mais que pareça nos humilhar, não faz senão engrandecer-nos; pois, assinalando o lugar que nos compete na natureza, mostra-nos o que nos é lícito pela ciência aspirar. O homem!... ultima verba da animalidade!" (Cabral, 1876, p.217-218).

O sentido dessa observação é muito claro: desqualificar uma epistemologia considerada ultrapassada e inadequada ao correto estudo da natureza humana e, na visão de Guedes 
Cabral, inimiga da própria investigação científica. Dever-se-ia, portanto, "arrancar o homem da Bíblia", nas palavras do próprio autor (Cabral, 1876, p.XXVII).

Ao atacar a versão bíblica do homem, Guedes Cabral também ataca a ideia da alma humana. Aceitar a alma imaterial seria conjuntamente concordar com a criação do homem por Deus, refletindo sua posição privilegiada na natureza. Ao mesmo tempo, seria aceitar que pensamentos/emoções/sensações estariam relacionados não a uma estrutura física mensurável do organismo, mas à própria abstração da alma. Esses dois pontos tanto estavam em conflito com as novidades contemporâneas do campo de estudo de Guedes Cabral, as disciplinas da fisiologia, embriologia e anatomia comparadas, quanto impossibilitavam que a medicina pudesse ter algum veredicto sobre as moléstias mentais.

Alinhado tanto com a institucionalização da medicina quanto com as questões teóricas da biologia, Guedes Cabral atacou a existência de uma alma imaterial de maneira resoluta. Ele trata gradualmente as consequências dessa nova epistemologia, de maneira que sua tese vai sendo aos poucos construída através de etapas logicamente arranjadas.

se a sensação ... é produto do cérebro, a 'volição fica até certo ponto implícita no fato da sensação'; a vontade fica aí como uma maneira de ser da sensibilidade.

Não? E por quê? Que há aí nisso de estranho porventura?

Compreende-se: depois, isto é, logo após o fenômeno da impressão, transmitida ao cérebro esta, aquele centro, impressionado agradável ou desagradavelmente, reage: é a percepção. 'Nesse conflito é que vai a vontade, esse movimento particular da trama cerebral - a volição' (Cabral, 1876, p.28; destaques nossos)'

Mais uma vez há uma grande semelhança entre a linha argumentativa de Guedes Cabral e a de Haeckel: assim como para este último, a volição, pelo fato de estar diretamente condicionada a causas materiais, é por elas determinada, seguindo uma cadeia de causalidade que leva as escolhas humanas diretamente à perturbação causada pelo movimento material de seus cérebros, talvez porque tome a palavra 'nutrição' por seu sentido literal, quando da suposta leitura dos mecanismos evolutivos enunciados na obra haeckeliana, Guedes Cabral imagina que até mesmo os alimentos selecionados na dieta podem determinar as escolhas do homem. O livre-arbítrio é uma quimera para o autor de Funções do cérebro.

Essa visão do lado psíquico humano traz consequências importantes para a medicina. Ao estabelecer ligação íntima entre as condições de vida e o pensamento humano, Guedes Cabral desenvolve a ideia que será, no início do século XX no Brasil, tema de muito debate dentro da atividade científica nacional: a questão do desenvolvimento da inteligência humana pelo exercício cerebral.

A ignorância mesma não será tambem até certo ponto uma moléstia, uma verdadeira astenia? O ignorante é o homem em que se não exercitaram convenientemente, totalmente os elementos do cérebro: há aí portanto uma verdadeira astenia do órgão, que provém da falta de material conveniente para aquela função orgânica. As impressões que são, como vimos, a matéria-prima do pensamento, 'debalde forcejam por ativar aquela máquina que se oxida à míngua de óleo' - 'esse óleo precioso do ensino lubrifica as molas e tanto perlustra a inteligência do homem!' (Cabral, 1876, p.202-204). 
Como podemos observar nesse trecho, em Funções do cérebro há preocupação sobretudo com a degeneração cerebral, ou seja, com problemas oriundos da má utilização do órgão. Essas ideias ganharão ainda mais evidência dentro das ciências nacionais especialmente no início do século XX, com o desenvolvimento das investigações de caráter eugênico. Segundo Nancy Stepan (2004, p.345-355), o movimento eugênico que se desenvolveu no Brasil entre o final dos anos 1910 e meados dos 1920 teve caráter mais sociológico do que propriamente biológico, preocupado principalmente com o papel do indivíduo dentro da sociedade. Sem ênfase nos caracteres biológicos das raças e, portanto, muito diverso do modelo anglo-saxão, a eugenia brasileira nesse período foi associada a problemas gerais envolvendo o comportamento da população, como conflitos familiares, educação sexual e alcoolismo. A peculiaridade brasileira seria explicada pela referência científica francesa de nossos médicos, que desenvolveram o programa eugênico nacional a partir da tradição 'neolamarckista' daquele país, prática essa que assumia uma teoria da hereditariedade com base na herança dos caracteres adquiridos e no mecanismo do uso e desuso. A indistinção nature/nurture ${ }^{5}$ decorrente dessa epistemologia provocou um conceito de eugenia absolutamente típico, refletido na máxima 'sanear é eugenizar' - a esperança era de que reformas sanitárias seriam capazes de melhorar o caráter hereditário da população, destruindo determinadas doenças e vícios de comportamento. Somado ao espírito positivista que dominou a intelectualidade brasileira nos últimos anos do século XIX, a nova 'ciência eugênica' reforçou a esperança de transformação do país pelo poder da educação: nesse caso, fundamentado em supostas bases teóricas, uma vez que o paradigma epistemológico 'neolamarckista' apontava para uma interferência direta de ações do meio na estrutura dos seres humanos.

Embora Funções do cérebro se situe um pouco antes do recorte histórico de Stepan, as primeiras décadas do Novecentos, há muito do espírito eugenista desse período nas ideias de Guedes Cabral. Percebe-se que o fim de sua argumentação é igual ao das personagens que promoveram o eugenismo no início do século XX: melhorar o povo, aprimorar sua capacidade física/mental. Por outro lado, Guedes Cabral representa uma continuidade de ideias entre seu período e aquele posterior. Segundo Barros (1986, p.10-14), o paradigma cientificista que dominou o último quartel do século XIX brasileiro tinha como uma de suas principais bandeiras a ênfase na transformação pela educação. A ilustração do povo garantiria, assim, de acordo com a filosofia comteana, a equivalência do Brasil ao estádio histórico daquelas nações intelectualmente mais desenvolvidas do mundo. Guedes Cabral parece incorporar a essa retórica de progresso pela cultura a ideia de melhoramento biológico do brasileiro, uma vez que, à semelhança da epistemologia chamada por Stepan de 'neolamarckista', não fazia distinção entre nature e nurture. A educação é o óleo que lubrifica a maquinaria cerebral: seu significado é ainda mais abrangente do que aquele que Barros aponta para as demais personagens do Oitocentos, pois trata-se de um mecanismo fisiológico, indispensável ao funcionamento adequado do corpo humano.

O homem, para Guedes Cabral, é apenas mais um animal e não possui alma. Embora pertença a um mundo fluido, em evolução, está submetido a limites estritos mantidos pela biologia da qual é constituído. Embora possa decidir e fazer escolhas, isto é apenas mais uma ilusão material proveniente de seu corpo. Como seria a sociedade ideal a abrigar esse 
homem? Aquela em que vive é adequada para si? Guedes Cabral não deixa essas perguntas sem resposta - há um novo conceito de sociedade em Funções do cérebro.

\section{Acabe-se com os códigos: a sociedade ideal}

Se, como vimos até aqui, todos os fenômenos da natureza são explicados em termos materiais, nada mais coerente do que esperar a manutenção desse viés materialista num olhar sobre a sociedade. É com base nessa proposta que Guedes Cabral procura fazer uma leitura alternativa da moral e dos valores da sociedade em que vive.

Primeiro que tudo, a ideia propriamente dita não pode ser, não é o produto da inteligência isolada de todas as cousas, mas "a conquista lenta e penosa dos combates intelectuais do gênero humano" em meio do mundo que o cerca. As ideias metafísicas, estéticas, morais, em suma, todas são, pois, resultados e não princípios.

'Tais ideias não são mais do que, ou meras convenções, ou o eco de puras necessidades fisiológicas', quando não verdadeiros caprichos sancionados.

'O bem é uma convenção, um pacto: o mal - uma relatividade do bem'. Não há mal absoluto. As ideias morais, portanto, que todas daí decorrem, não são mais do que consequências do estado social do homem e das relações do homem para com suas mesmas propriedades. 'Primitivamente, antes de toda agregação, de toda sociedade, o homem desconheceu por certo todas estas noções, se bem que sentisse algumas das impressões que a determinam'. ...

E o direito nasceu desse conflito de necessidades humanas. 'O bem ficou, pois, convencionado, isto é - o quociente de satisfação dessas necessidades' (Cabral, 1876, p.160-161; destaques nossos).

Cabral entende a moral como mera convenção, sem nenhum critério objetivo que não seja a satisfação das necessidades fisiológicas do organismo humano. Embora essa posição seja derivada do evolucionismo, ela não representa consenso entre os adeptos da teoria. Ainda que Spencer e Haeckel admitissem uma transposição direta das leis naturais para o domínio social humano, Darwin se opunha ferrenhamente a tal proposta (Desmond, Moore, 2001). Admitir uma explicação materialista para a formação da sociedade e da moral humana não equivalia, para o naturalista, a admitir que os valores virtuosos devessem ser considerados mera convenção. Eles eram mais do que isso, representavam a peculiaridade humana de elevada compreensão do mundo, conforme escreveu em 1871: "A natureza moral do homem atingiu o seu nível atual em parte pelo progresso de suas faculdades raciocinantes e, consequentemente, da opinião pública certa" (Darwin, 1982, p.704). Em seu primeiro artigo, Darwin exalta o poder civilizatório do cristianismo, considerando-o a causa do progresso moral observado entre os nativos das terras do Taiti (Gould, 1993). Esse artigo é um bom exemplo da discordância do naturalista inglês com relação ao espírito intelectual geral de sua época, que considerava os homens inferiores condenados a sua biologia. A opinião pessoal de Darwin contrastava com as consequências imediatas de sua teoria evolutiva, deslegitimando muitas das críticas de seus contemporâneos: não é verdade que ele considerava a moral humana errônea e/ou desnecessária.

Para Frezzatti Jr. (2001, p.116-118), há clara descontinuidade entre as ideias darwinianas acerca do progresso biológico e social e aquelas relativas ao mundo biológico. O autor defende 
que, embora Darwin negue através de sua teoria a existência de um estado e/ou estrutura ideal a ser atingida pelos organismos através de sua evolução, isso não é considerado sobre a evolução da moralidade e dos valores humanos. Ainda que cada sociedade possua valores diferentes, Darwin acredita, segundo Frezzatti Jr., que há uma meta moral a ser atingida, perspectiva derivada da ideia do bem como valor absoluto. Essa posição representa, portanto, uma descontinuidade em relação a sua teoria sobre o mundo biológico, uma vez que este é entregue à contingência, inexistindo qualquer meta teleológica ao longo do processo evolutivo. Ainda que a inteligência humana seja oriunda da evolução da matéria, através de condições naturalistas e contingentes, o desenvolvimento da organização social teria impulsionado os valores em direção a um fim bem definido e inequivocamente virtuoso. As boas maneiras dos povos modernos representam, nesse contexto, um progresso real na comparação com as sociedades primitivas e/ou povos selvagens ainda existentes no mundo, como os fueguinos e os taitianos.

O conceito de moralidade de Guedes Cabral é inteiramente distinto do darwiniano. Ao declarar a relatividade do bem, o autor de Funções do cérebro quer dizer que não há valores universais que devam ser seguidos, ou metas morais a atingir. A sociedade, segundo sua perspectiva, não se pode prender a essas considerações, oriundas de conceitos metafísicos incompatíveis com a investigação do mundo natural. O conceito da moral humana deve ser naturalístico, com base na fisiologia humana: o que é bom ou certo o é porque agrada ao organismo; o que é mau ou errado o é porque entra em choque com esse organismo. O corolário dessas ideias é a reformulação da sociedade da maneira como a conhecemos: nossos códigos, valores e ideias devem ser repensados em vista dessa nova perspectiva. É bem conhecido o temor de Darwin quanto à transposição de sua teoria evolutiva ao mundo social, principalmente quando pensava em sua apropriação pelos revolucionários ingleses e os materialistas alemães, Haeckel, Büchner e Vogt (Desmond, Moore, 2001, p.559-560). Guedes Cabral materializa, assim, alguns dos maiores receios de Darwin, procurando desautorizar a moral vigente em consequência de suas ideias evolucionistas/materialistas.

Para o autor de Funções do cérebro, uma das consequências do novo olhar lançado sobre a moral é a relativização do crime. Se não existe uma moral absoluta e o homem define o bem pela satisfação de suas necessidades fisiológicas, se não há livre-arbítrio e as ações humanas são determinadas pelas nuanças do movimento material, aquele que erra não pode ser culpado pelos seus atos: logo as leis são criações esquizofrênicas, assim como as punições sugeridas.

Ora, que razão há então para não admitir-se que o longo e frio silêncio de uma prisão atuando mais e mais sobre o cérebro, dê em resultado a sua volta ao exercício normal? Depois, esses criminosos são apenas doentes temporários.

E quereis a prova daquilo? É que não rara vez, a maioria delas, é o lado contrário que se observa: os criminosos reclusos saem das masmorras três vezes piores (Cabral, 1876, p.205).

O criminoso é um doente. Para Guedes Cabral sua prisão é um desvio do foco verdadeiro do problema. Mais do que isso, a adoção das leis tal como estabelecidas prejudica a própria sociedade, já que os contraventores não se recuperam e ainda pioram em função do regime prisional. Essas observações do autor de Funções do cérebro, entretanto, não podem ser tomadas 
fora de seu escopo ideológico. De acordo com Lilia Schwarcz (2003, p.165-180), o debate acerca da contribuição nature/nurture em relação ao crime no final do século XIX no Brasil foi algo que refletiu dicotomia bem demarcada: de um lado, os médicos das Faculdades de Medicina do Rio de Janeiro e de Salvador; de outro, os bacharéis das Faculdades de Direito de São Paulo e Recife. Enquanto o primeiro grupo insistia na importância dos caracteres biológicos para a atividade criminosa, em grande parte influenciado pelas escolas craniométrica de Paul Broca e frenológica de Cesare Lombroso, os bacharéis apontavam o caminho da homogeneização dessas diferenças naturais por meio das leis por eles homologadas. Schwarcz entende que os médicos, em face desse importante debate social, se transformaram em médicos/políticos ou médicos/cientistas sociais, devido a sua atenção especial em relação às consequências de suas atividades científicas para o regime político do país, em tese semelhante à de Alonso (2002) acerca da interseção intelectual/política das personagens desse período. Schwarcz reserva ainda lugar especial aos médicos baianos na criação de uma antropologia criminal no Brasil, que teve entre o final do Oitocentos e início do século XX em Nina Rodrigues seu maior representante. Se observarmos Funções do cérebro e suas ideias à luz dessa perspectiva, a continuidade de suas propostas com aquelas popularizadas pela escola de medicina criminal referida por Schwarcz salta aos olhos: o ponto é demonstrar o quanto o crime é um desvio biológico, um problema centrado na natureza, que pede intervenção especializada dos discípulos de Hipócrates.

Por outro lado, se somarmos a esse quadro a questão da profissionalização médica no Brasil, veremos que Guedes Cabral se insere num contexto ainda mais amplo, de valorização da medicina nacional e busca de sua efetiva institucionalização. Segundo Edler (1992, p.17-18), a busca da profissionalização da medicina brasileira relacionou-se intimamente com a demonstração da importância dessa prática, bem como com a valorização dos médicos como profissionais detentores da expertise necessária ao progresso do país. Além de almejarem as reformas que consideravam necessárias à transformação da medicina em prática efetivamente científica, diferenciando-se assim de curandeiros e outros terapeutas populares, os esculápios procuraram demonstrar a importância de seu papel social, que consideravam fundamental em relação a questões de saúde, doença, ordem, justiça e remodelação higiênica das cidades. Em resumo, os médicos procuraram apresentar-se como responsáveis pela qualidade de vida geral da população brasileira, da qual poderiam cuidar afastando o estigma de um país atrasado e condenado à estagnação intelectual. Nesse sentido, podem-se observar em Funções do cérebro os mais variados reflexos dessas propostas: a necessidade da transformação da medicina em 'verdadeira filosofia', rejeitando dogmas religiosos e filosofias espiritualistas, afirmando-se como prática efetivamente científica; a demonstração da suposta inocuidade das leis em relação aos caracteres biológicos humanos; a importância do papel do médico no progresso do homem brasileiro. Guedes Cabral encontrava-se, portanto, plenamente integrado às questões científicas/políticas de sua classe profissional, estendendo suas ideias muito além do limite intelectual estabelecido pelas que apresentou em Funções do cérebro.

O olhar de Guedes Cabral dirigido ao criminoso merece ainda outra consideração especial. Curiosamente, ele não desenvolve uma ideia de seleção artificial da espécie humana, ou seja, a seleção de indivíduos com características proveitosas e a eliminação daqueles que se apresentassem biologicamente inferiores. Embora se afaste das ideias de Darwin em algumas oportunidades, por exemplo, quando se refere à seleção natural como parte de uma 
teleologia do progresso natural ou quando afirma a própria relatividade da moral, Guedes Cabral apresenta proposta em relação aos indivíduos biologicamente desfavorecidos muito semelhante àquela do naturalista inglês. Nos dois pensadores, vemos a ideia comum de crença no aperfeiçoamento do indivíduo em oposição a sua eliminação, a aposta na transformação de biologia supostamente inferior através de práticas que mesclem os domínios nature/nurture. Mesmo considerando que a educação só pode "'até certo ponto' ... forçar essa muralha construída e cedo fechada pela natureza" (Cabral, 1876, p.63-64, destaques nossos), o médico baiano não chega a admitir, como o faz explicitamente seu colega paulista Miranda Azevedo a seleção artificial da espécie humana (Cid, 2004). A visão de Guedes Cabral em relação ao criminoso é característica do que vimos até aqui ao longo de Funções do cérebro: não há linha filosófica específica que possa ser identificada com o autor, mas sim um apanhado geral do evolucionismo, esse cumprindo o papel de grande base a partir da qual são montadas suas teorias acerca do cérebro e de suas funções.

\section{Considerações finais}

Ao apresentar evolução/darwinismo mais como visão de mundo do que propriamente discussão restrita à esfera biológica, Guedes Cabral expõe a interseção político/intelectual apontada por Alonso como característica das personagens do último quartel do Oitocentos brasileiro. Longe de permanecer restrito ao campo da biologia, Guedes Cabral invoca o evolucionismo para discussões em torno do conceito de ciência, do papel social dos médicos e dos bacharéis, da inocuidade das crenças espiritualistas, da compreensão da volição humana, da importância do progresso e do exercício cerebral. Essa posição insere o autor de Funções do cérebro naquelas questões retomadas por Edler (1992) e Schwarcz (2003), que apontam para a institucionalização da medicina nacional e a disputa pela hegemonia intelectual entre os médicos e os bacharéis do curso de direito. Acreditamos que, assim como o sucesso científico do pasteurianismo representou importante argumento para a modernização das faculdades oitocentistas e a profissionalização da medicina, como apontam Edler (1992) e Benchimol (1999), o darwinismo defendido por Guedes Cabral se dispõe a função análoga, enfatizando novo proceder materialista para a investigação biológica em contraposição ao esgotado modelo espiritualista.

Se fora da esfera biológica Funções do cérebro é interessante exemplo do momento histórico do final do século XIX brasileiro, no contexto da biologia a obra também dialoga com questões que rondavam a ciência nacional contemporânea. Um dos primeiros trabalhos evolucionistas do país, Funções do cérebro aponta para dois desenvolvimentos teóricos que ocuparam lugar importante nas discussões científicas do início do século XX. Em primeiro lugar, a ênfase de Guedes Cabral na importância da instrução ambiental em oposição à seleção artificial, substanciando o debate a respeito daqueles indivíduos fora do padrão social almejado, pode ser observada também no desenvolvimento da investigação eugênica no início do século XX realizada por Renato Kehl, Roquette-Pinto e outros pesquisadores nacionais (Stepan, 2004). Embora a 'eugenia negativa', que pregava a eliminação dos inaptos, também tenha ocorrido nos debates do meio científico brasileiro do início do século XX, a historiografia aponta para o predomínio da versão 'positiva' da eugenia, que admitia um progresso da natureza humana 
através da mudança de sua biologia por procedimentos socioculturais. Nesse sentido, cabe observar o novo significado da educação nesses debates, que extrapola a esfera cultural e passa a ter sentido fisiológico, importante para a biologia do homem. Como procuramos destacar neste trabalho, encontramos o significado de 'educação' de maneira muito clara na argumentação de Guedes Cabral de que um cérebro estagnado representava mais do que um indivíduo ignorante; representava de fato o início de um processo degenerativo. Outra questão levantada por Funções do cérebro e relevante no debate científico nacional foi o desenvolvimento da ideia de uma medicina criminal. Representada principalmente pelos trabalhos de Nina Rodrigues - vinculado à Faculdade de Medicina da Bahia, em que se doutorou Guedes Cabral -, a medicina criminal também foi linha teórica importante nas ciências brasileiras do início do século XX (Schwarcz, 2003, p.172-173). As preocupações de Guedes Cabral com a importância da medicina para a investigação criminal apontam, portanto, para o desenvolvimento teórico que se deu na Faculdade de Medicina da Bahia nos primeiros anos do século XX, o que parece indicar que as investigações nesse sentido já ocorriam desde o último quartel do século XIX.

Acreditamos que a proposta de Funções do cérebro, portanto, vá muito além do que seu título sugere. A obra é exemplo muito interessante de como aquelas teorias intelectuais do final do século XIX se misturaram inextricavelmente a propostas políticas, impossibilitando nítida demarcação entre as duas esferas. Diferente do que pode parecer à primeira vista, uma tese sobre as funções do cérebro e discussões pertinentes ao assunto, o trabalho de Guedes Cabral revela-se também possuidor de proposta ideológica convicta, voltada para a afirmação de sua profissão e de suas posições políticas.

\section{NOTAS}

${ }^{1}$ Este artigo originou-se da dissertação desenvolvida no Programa de Pós-graduação em História das Ciências e da Saúde - Fundação Oswaldo Cruz, Casa de Oswaldo Cruz, intitulada As funções de Funcções do Cerebro (1876): um estudo do evolucionismo de Domingos Guedes Cabral (1852-1883), orientada pelo doutor Ricardo Waizbort.

${ }^{2}$ Utilizo, em concordância com Frezzatti Jr. (2001), o termo 'darwiniano' para referência específica às ideias de Darwin e 'darwinista/darwinismo' para aquelas ideias que remetam de alguma forma à linha evolucionista desenvolvida a partir dos trabalhos de Darwin. O darwinismo pode abranger múltiplos conceitos, nem todos necessariamente desenvolvidos pelo naturalista inglês. Cabe ainda ressaltar que, embora o darwinismo seja um tipo de evolucionismo, este não se esgota naquele.

${ }^{3}$ A associação da filosofia evolucionista ao experimentalismo pode parecer estranha, sobretudo se considerado que a metodologia heterodoxa de Darwin foi uma das principais críticas feitas a The origin of species. No entanto, o evolucionismo darwinista logo seria reconhecido como plenamente científico, inovando, aliás, por apresentar nova metodologia, o método hipotético-dedutivo (Mayr, 1998, p.582-583). Dentro do debate sobre as consequências do evolucionismo para os mais variados campos, Guedes Cabral não trazia dúvidas sobre a cientificidade dessa filosofia, uma vez que a considerava plenamente substanciada pelas demais disciplinas positivas: "O homem é, pois, apenas um macaco aperfeiçoado ... Esta verdade não assegura-a somente a zoologia: prova-a demais a anatomia e fisiologia comparadas, a arqueologia, a antropologia, e, além delas, uma ciência moderna do maior peso - a embriologia." (Cabral, 1876, p.218219). Não é sem propósito que Guedes Cabral cita zoologia, anatomia, fisiologia, arqueologia, antropologia e embriologia como escudos de seu argumento: são todas ciências institucionalizadas e que legitimam as recentes ideias evolucionistas. A evolução biológica para Guedes Cabral era, portanto, uma teoria fortemente alicerçada em bases experimentais, reforçando ainda mais a originalidade de suas conclusões.

${ }^{4}$ Nessa e nas demais citações de obras em inglês, foi fornecida uma tradução livre. 
${ }^{5}$ Nature, que entendo como natureza, e nurture, que entendo como contraposição ao que é inato ou 'natural' dos seres vivos. Esses termos são frequentemente utilizados por pesquisadores para enfatizar ou uma perspectiva centrada na biologia do indivíduo (nature) ou uma perspectiva centrada no que o indivíduo tem de particular em sua existência como um ser histórico (nurture). Para Stepan (2004), a cujo argumento me refiro no trecho, a eugenia brasileira não distinguia o par nature/nurture, ou seja, não delimitava o que entedia ser da natureza biológica dos seres humanos ou o que poderia ser resultado de causas históricas.

\section{REFERÊNCIAS}

ALMEIDA, Ronnie Jorge Tavares.

Religião, ciência, darwinismo e materialismo na Bahia imperial: Domingos Guedes Cabral e a recusa da tese inaugural Funcções do Cerebro (1875). Dissertação (Mestrado) - Universidade Federal da Bahia, Salvador. 2005.

ALMEIDA, Ronnie Jorge Tavares; EL-HANI, Niño Chabel.

Por que a tese de Domingos Guedes Cabral foi recusada pela Faculdade de Medicina da Bahia em 1875? Revista Brasileira de História da Ciência, Rio de Janeiro, v.3, n.1, p.44-67. 2010.

ALONSO, Ângela M.

Idéias em movimento: a geração de 70 na crise do Brasil império. São Paulo: Paz e Terra. 2002.

BARROS, Roque Spencer Maciel de.

A ilustração brasileira e a idéia de universidade. São Paulo: Convívio; Edusp. 1986.

BENCHIMOL, Jaime Larry.

Dos micróbios aos mosquitos. Rio de Janeiro: Editora Fiocruz/UFRJ. 1999.

BIZZO, Nélio.

Ensino da evolução e história do darwinismo. Tese (Doutorado) - Faculdade de Educação/ Universidade de São Paulo, São Paulo. 1991.

CABRAL, Domingos Guedes.

Funções do cérebro. Bahia: Imprensa Imperial. 1876.

CID, Maria Rosa.

O aperfeiçoamento do homem por meio da seleção: Miranda Azevedo e a divulgação do darwinismo, no Brasil, na década de 1870 . Dissertação (Mestrado) - Casa de Oswaldo Cruz, Rio de Janeiro. 2004.

COLLICHIO, Teresinha Alves Ferreira.

Miranda Azevedo e o darwinismo no Brasil. São Paulo: Itatiaia. 1988.

DARWIN, Charles Robert.

A origem das espécies. São Paulo: Itatiaia. 1985.

DARWIN, Charles Robert.

A origem do homem e a seleção sexual. São Paulo: Hemus. 1982.

DARWIN, Charles Robert.

A origem das espécies. São Paulo: Hemus. 1979.
DESMOND, Adrian; MOORE, James.

Darwin: a vida de um evolucionista atormentado. São Paulo: Geração Editorial. 2001.

EDLER, Flávio Coelho.

As reformas do ensino médico e a profissionalização da medicina na Corte do Rio de Janeiro: 1854-1884. Dissertação (Mestrado) - Universidade de São Paulo, São Paulo. 1992.

FREZZATTI JR., Wilson Antonio.

Nietzsche contra Darwin. São Paulo: Discurso; Unijuí. 2001.

GOULD, Stephen Jay.

Dedo mindinho e seus vizinhos: ensaios de história natural. São Paulo: Companhia das Letras. 1993.

GREENE, John C.

Science, ideology and world view: essays in the history of evolutionary ideas. Berkerley: University of California Press. 1981.

GUALTIERI, Regina Cândido Ellero.

O evolucionismo na produção científica do Museu Nacional (1876-1915). In: Domingues, Heloísa Bertol; Sá, Magali Romero de; Glick, Thomas (Org.). A recepção do darwinismo no Brasil. Rio de Janeiro: Editora Fiocruz. p.4596. 2003.

HAECKEL, Ernst.

A história da criação natural. Porto: Lello \& Irmão. 1961.

LAMARCK, Jean-Baptiste.

Zoological philosophy. Chicago: The University of Chicago Press. 1984.

MAYR, Ernst.

O desenvolvimento do pensamento biológico. Brasília: Editora UnB. 1998.

ROMERO, Sílvio.

A filosofia no Brasil. In: Vita, Luís Washington. Obra filosófica. Rio de Janeiro: José Olympio; Edusp. 1.ed. 1878. 1969.

SCHWARCZ, Lilia Moritz.

O espetáculo da miscigenação. In: Domingues, Heloísa Bertol; Sá, Magali Romero de; Glick, Thomas (Org.). A recepção do darwinismo no Brasil. Rio de Janeiro: Editora Fiocruz. p.165-178. 2003. 
SPENCER, Herbert.

Do progresso, sua lei e sua causa. S.l.: eBooksBrasil. Disponível em: http://www.ebooksbrasil.org/ adobeebook/progresso.pdf. Acesso em: 13 mar. 2012. 2002.

SPENCER, Herbert.

First principles. S.l.: s.n. Disponível em: http:// www.dominiopublico.gov.br/download/texto/ mc000255.pdf. Acesso em: 13 mar. 2012. 1862.
STEPAN, Nancy Leys.

Eugenia no Brasil, 1917-1940. In: Hochman, Gilberto (Org.). Cuidar, controlar, curar: ensaios históricos sobre saúde e doença na América Latina e Caribe. Rio de Janeiro: Editora Fiocruz. p.331-392. 2004. 